\title{
Public domain and democracy in the digital age
}

\section{Patricia Mindus and Nils Säfström}

To say that a piece of information or a creative work is "in the public domain" implies freedom of access and use. Public domain ensures ease of access to information that traditional intellectual property regimes often do not. Ensuring the right to information is of crucial democratic concern. Being able to freely access and use information and cultural data seems to be a prerequisite for the demos to genuinely and robustly exercise kratos - its ability to rule.

Public domain plays a two-fold role in democratic politics. As a building block of the public sphere, it supports the creation and maintenance of the latter. On the one hand, the public domain provides a repository of informative materials and cultural data, necessary for citizens to shape their own judgments on public life. On the other hand, it ensures dissemination of information in the public sphere that may be relevant for political, historical and cultural reasons. Public domain functions both as a prerequisite for and a result of democratic political action and allows for both top-down and bottom-up approaches.

Basic to our understanding of contemporary democracy, public domain is a precondition for a well-functioning political life - but how this occurs and what we are willing to pay for it are unclear. What information can be exploited, by whom, under what circumstances? And what information should be used? What do our choices on these matters imply for the rights involved, which stretch from the right to information, to privacy, freedom of expression, and freedom of opinion, which many democratic theorists hold to be a very special kind of propedeutical right for the exercise of political rights in a democracy.

Entering the digital age has made the role of the public domain in democratic life more visible and at the same time more contentious. Digital technologies are disruptive in many ways: they teach us who we are and who we can be. The data involved in defining these identities - that amount to meaningful information (only) for some agents - are such stuff as politics are made of. This makes the Internet a fascinating realm: it blurs the distinction between the public and the private in many different ways. For some, the Internet is the ultimate political frontier. We all leave copious traces everyday about our present and about our past - what are their value? A lot, if we are to believe anticipatory computering, i.e. the capacity to foresee choices on the basis of past preferences. In Orwell's words, "He who controls the past controls the future. He who controls the present controls the past." Today, that person is ever more often a data scientist.

In many jurisdictions, enclosures have put the boundaries of the public domain under stress. Governments are increasingly subjected to demands to expand the public domain by opening and digitalizing official records and archives, to develop new business areas such as Public Sector Information (PSI) and new communication venues with citizens. These demands are bound to raise concerns about security and privacy, but most interestingly they challenge the very way we conceive of public information and the principle it is founded on. This is the principle of publicity that has shaped the public sphere in which democratic 
societies have evolved over the centuries. Disagreement as to what counts as open information, what information should be in the public domain, how the public domain informs the public sphere, and how it impacts constitutional design in democratic polities is to be expected. But first and foremost, we can expect discord about what public domain policies are desirable.

Indeed, the transformation of the public domain comes with a blurring of its boundaries - the determination of which has now become a politicized issue. As a consequence, the politics of intellectual property and the legal determination of IP regimes are becoming an issue for democratic politics.

This explains the decision to put together a special issue on "Public Domain and Democracy in the Digital Age".

The topic raises questions in a number of academic fields: it lies at the scholarly intersection between - at the very least - philosophy, legal studies, sociology, political science, ICT studies and STS. By bringing together scholars from various areas of research, this special issue aims to bridge outlooks and offer an interdisciplinary approach to an issue that to various degrees affects all citizens of present-day democracies.

The papers collected in this special issue were originally presented at the international conference Public Domain and Democracy in the Digital Age held in Uppsala, Sweden, on 18-19 September 2014. The conference was recorded, and each talk with the follow-up debate can be viewed at http://media.medfarm.uu.se/play/kanal/226. The event was coorganized by the Philosophy Department at Uppsala University (Patricia Mindus) and the Swedish Law and Informatics Research Institute at Stockholm University's Faculty of Law (Cecilia Magnusson Sjöberg), and sponsored by KUSKO at Uppsala University's Faculty of History and Philosophy, the Edvard Cassel Foundation at Stockholm University's Faculty of Law, and the Wenner-Gren Foundation. A selection of the videos was picked up by the Swedish Educational Broadcasting Company (UR), which is part of the Swedish public service broadcasting group, and televised on 12 April 2015 in slightly edited versions (available at http://ur.se/Produkter/188532).

In the opening article of this special issue, "Algorithmic regulation and the global default: Shifting norms in Internet technology”, Ben Wagner explores the algorithms governing the coded objects we use in our day-to-day lives, from credit cards to airplanes. Our understanding of how these algorithms are regulated is poor, Wagner argues, leading us to think they are normatively neutral. This, however, risks obscuring the fact that there is power embedded in their design that needs demystifying.

In the second article, "Law and algorithms in the public domain", Dag Wiese Schartum discusses the relationship between traditional legislative processes on the one hand, and the development of information systems to implement legislation on the other. It could be argued that certain aspects of systems development processes should be regarded as quasilegislation. Schartum then investigates possible ways of changing this process, with a view to increasing and improving openness and political involvement in tasks that are today often regarded as mere automatic implementation.

In the third article, "Between 250 years of free information and 20 years of EU and Internet”, Inger Österdahl describes the conflict between Sweden's constitutionally based right of access to documents and the more privacy-protective EU law. Since entering the EU in 1995, Sweden has been caught between two differing traditions of openness and transparency: the national and the European traditions. The first is centuries old and is more permissive than its more recent European counterpart, which is more restrictive. Sweden 
will be called upon to resolve this situation, and Österdahl points out that Swedish official inquiries and the EU Regulation will provide an indication of the route forward in 2016.

In the fourth article entitled "Public domain as a master frame?", Sebastian Haunss asks whether, and to what extent, the concept of the public domain, or the commons, has become a master frame, playing a unifying role for actors involved in various mobilizations against strong intellectual property rights. To answer the question, he looks at two of the largest movements in which intellectual property rights have been disputed, and the framing strategies such movements have used: the global mobilization on access to medicines, and the European conflict over software patents. Haunss presents his findings and closes the article with a more general comparative discussion of the framing strategies used, and how they should be interpreted.

In the fifth article that wraps up this special issue, "Defining the public domain in economic terms: Approaches and consequences for policy", Kristofer Erickson reviews two predominant economic theories that shape how policymakers discuss the public domain in debates about intellectual property reform. The first is a welfare economics approach, which weighs increases in producer and consumer surplus under different policy configurations; the second an economics of innovation approach, which considers the value of the public domain as a reservoir of ideas for individuals and firms. Erickson argues that economic definitions should be augmented by a consideration of the democratic requirement of access to information.

In the Open Section of this issue, the paper "Refleksjonsgrupper i etikk: «Pusterom» eller læringsarena" ("Ethics reflection groups: Just a 'time out' or a learning arena?") by Siri Tønnessen, Lillian Lillemoen and Elisabeth Gjeberg argues that the reflection being carried out in such groups appears to function more as a "time out" than a learning arena for ethical reflection. The authors undertake a critical discussion of this practice within the context of the huge financial resources that the Norwegian authorities have invested in the project. The authors conclude that this practice does not seem to contribute to the intended effect, i.e. enhanced ethics competence in Norwegian community health care. The main reasons are due to the facilitators being neither sufficiently well trained in methods of reflection, nor sufficiently well followed up on.

Another Open Section contribution is the article "The ethics of wild animal suffering" by Ole Martin Moen, in which he argues that we should take the suffering of wild animals seriously as an ethical issue. Even if such suffering is not caused by human action or the magnitude of such suffering is so large that it is hard for us to grasp, the reasons that compel us to care for fellow humans who suffer from natural causes must apply if we reject anthropocentrism. The author also criticizes the one-sidedness of caring only for the suffering of captive animals when the magnitude of wild animal suffering is much greater.

This issue also includes Knut Jørgen Vie's book review of Moral reasoning at work: Rethinking ethics in organizations by Øyvind Kvalnes (Palgrave Macmillan, 2015. 108 pages).

We would like to thank the resident editors at Etikk i praksis - Nordic Journal of Applied Ethics and all reviewers for their help with preparing this special issue. 


\section{Guest editors for Etikk i praksis 1/2016}

Patricia Mindus is Associate Professor of Practical Philosophy at Uppsala University and Research Associate at the Swedish Law and Informatics Research Institute in Stockholm. Her research interests include inter alios democratic theory and Internet governance.

E-mail: patricia.mindus@filosofi.uu.se.

Nils Säfström is a $\mathrm{PhD}$ candidate in Practical Philosophy at the Department of Philosophy, Stockholm University. He works on issues in ethics and political theory and specializes in metaethics.

E-mail: nils.safstrom@philosophy.su.se 